\title{
Comparing the Effect of Schema-Based Education and Social Problem Solving Training on Social Competence and Expressions of Identity in Adolescents
}

\author{
Elahe Elahi \\ PhD student Islamic Azad university Tehran central branch,Tehran, Iran Elaheelahi4040@gmail.com \\ Mojgan Sepahmansour* \\ Associate professor Islamic Azad university Tehran central branch, Tehran, Iran \\ drsepahmansour@yahoo.com \\ Fatemeh Golshani \\ Islamic Azad university Tehran central branch, Tehran \\ Susan Emamipour
}

Islamic Azad university Tehran central branch, Tehran

\section{Doi:10.5901/mjss.2016.v7n5s1p64}

\section{Abstract}

\begin{abstract}
This study aimed to compare the effectiveness of schema-based education and social problem solving training on social competence of adolescents. The study population included all high school female students in the first course are studying in the academic year 2015-2016 in the city of Arak. The multi-stage cluster sampling method was used. At least 50 people: 25 people Schema-based training group and 25 were in the group of social problem solving training. Data were analyzed using multivariate analysis of variance. The results showed that comparing schema-based education and treatment of problemsolving therapy improve the three components of social competence; cognitive skills, emotional skills, behavioral skills of female students are effective. However, the impact and effectiveness of both treatment components motivational skills are relatively equal and the difference between the two treatment groups was observed in terms of the effectiveness of social competence motivational skills. Schema-based education and treatment of problem-solving therapy compared with the styles on upgrading the components of identity; early, late and chaotic school students with low social competence are more effective. However, in the field of advanced identity style impact and effectiveness of both treatment groups was relatively equal and different both in terms of their effectiveness. Schema-based training has a significant and positive effect on social competence of adolescents
\end{abstract}

Keywords: schemas-based education, social problem solving training, social competence, identity states, adolescents

\section{Introduction}

Along with the physical and mental development, family and community expect from the young rises so that they are due to social life, part of his desire to limit and within the framework of social norms and grouped (Lee Tian, 2014). The study of psychological problems in adolescence is very important social skills such as social competence as well as cases of identity in adolescents are a very important feature. Identity in adolescence as well as physical growth, cognitive, social and emotional crucial is important. One of the famous psychologists who called him the "identity" in adolescence is associated with Ericsson. However, the quality and quantity of human experience, personality traits and environmental changes, in the face of life's challenges leave a lasting mark and even the identity of adolescents as well. Special skills gradually institutionalized, can occur in people who have accompanied him at odds stressful situations (Moos \& Billing, 1990). Another important social skills that is very important in adolescence and maturity, social competence, so that as one of the most important goals of education in family and school have always considered (Carl Haynes, 2012) in the definition of social competence can be said, as the ability to understand others under a defined social interaction and communication. Therefore, social competence is each individual interacts with others and their social environment (Anme et al., 2014). Social competence, personal independence and social responsibility implement human performance ability. 
In other words, social competence, self-care ability, helping and caring for others (Abolghasemi, 2011). In many countries in order to promote mental health and prevention of social problems in adolescence, training is effectiveness in running schools. Yang (1998) with an emphasis on schemes stated that the scheme may be at a stage when inactive and then as a result of a change in the type of inputs received from the environment, they gain energy and become active quickly. This bias in our interpretation of events, and these biases in psychopathology for interpersonal misunderstandings, distorted vision, false assumptions, unrealistic goals and expectations are expressed (Yang and Glohsky, 2002). Few studies have shown that early maladaptive schemas between two variables in different areas and there is a significant relationship between identity and states by early maladaptive schemas and identity styles are different that often arise in the first years of life is predictable (Beyers W, Goossens L., 2009; Faber AJ, et al., 2013). It is known that early maladaptive schemas that to reach the teenage years are stable at high levels in the formation of identity style are effective. With that in mind, the schemas in childhood and family influence on the relationship between early maladaptive schemas and identity to the identity and atmosphere of the system family, the school, parents and teachers how to interact with children and adolescents affected, strategies to raise children and adolescents be effectively involved in the formation of our identity (Ammani, 2013).

Other notable skills in the study are social problem solving skills. Problem solving is a critical skill for life in the present day. In most communities, all believe that emphasis should be on improving problem-solving skills (Shahbazi and Heidari, 2012).

Social problem solving skill that can be its effect in reducing these disorders considered (Bygam and Power, 2012). This ability as an important mediator of depression and anxiety disorders is not known. Problem solving cognitive behavioral therapy a person or group trying to provide an effective solution to problems of everyday life. The problem arises when a person has a purpose but no clear way to access it. Solution, the answer comes from the process of problem solving that can be applied in particular situations is problematic (Marlow, 2011). Social problem solving is structural unit and multidimensional and complex structures of different abilities (Dezoorila, 1990-2003). In the basic model assumed of two independent components whose social problem solving orientation and problem solving skills is formed which later became the problem solving (Byani et al., 2012). In general, studies on improving the effectiveness of self, self-esteem, stress management, crisis of identity, motivation and depression in adolescents and adults (Stephenson, 1995; Tellador, 2013 Taj Jawaheri, 2014). Behavioral skills are one way of dealing with the problem of identity in this way the individual roles and various behavioral methods of training teaches these skills including the conduct of problem-solving manner. The people have a better education, better replication occurs and people will be more positive identity (Nasiri, 2011). Social problem solving skills in young people is one of their basic needs, for the teens in your life you encounter various problems and issues, if you do not have the ability to solve problems may face larger and more complex problems. Nezu cognitive-behavioral problem solving method 1996, during people strategies for coping with difficult situations faced in life creating or discover known (quoted by Llobet, 2014). When people have the opportunity and ability to deal with global issues and innovative solutions, which are primarily managed through a unity orientation "stable identity", are reached in the first place, or should have solved the problem and your problem (Nasiri, 2014). Various studies also show that life skills including cognitive skills, the adequacy of emotional, behavioral and mental set of motivational skills to improve the social competence of the students. Social problem solving skills can enhance the skills and thus improve the quality of life of students is effective (Kazemi et al., 2011). Compare proprietary research conducted in the field of education based on two variables Schema and social problem solving, social competence and identity of adolescents is very limited cases considering the above, the aim of this study was to compare the effects of the scheme education and training, social problem solving, social competence and states the identity of adolescents. Also according to research theoretical framework discussed and considered the following assumptions:

\section{The Main Hypotheses}

1. There is a significant difference between the effectiveness of Schema-based education and, social problem solving training on social competence in adolescents.

2. There is a significant difference between the effectiveness of Schema-based education and, social problem solving training $n$ scenarios identity of adolescents.

\section{Sub-Hypotheses}

1. Schema-based education has a significant impact on adolescent social competence.

2. The social problem solving has significant effect on adolescent social competence. 
3. Schema-based education has a significant effect on adolescent identity scenarios.

4. Social problem solving has significant effect on adolescent identity states.

\section{Method}

This study aimed to compare the effectiveness of schema-based education and social problem solving training on social competence and states the identity of the adolescents in the academic year 2016-2015 was conducted. The population in this study included all high school female students in the first course in the academic year are studying in 2016- 2015 in Arak city. Initial investigation showed the population of 10928 people. The multi-stage cluster sampling method was used which means two high schools the in city of Arak were randomly selected and then the first round of classes in each school, two classes were randomly selected. Then in each school, one class to another class Test 1 and Test 2 was considered. The class of 25 students per school students in the experimental group 1 (with training based on schemas) and 25 patients in the experimental group 2 (with social problem solving training) in total, 50 members constitute the study sample. The groups responded to the study questionnaire. Data using multivariate analysis of covariance were analyzed using SPSS software.

\section{Research Tool}

Social competence: Social competence in the study by the Social Competence scale (1990) will be evaluated. KARAMI and Prendin in finding that it was the norm for internal consistency, Cronbach's is $88 \%$. The social competence questionnaire on 4 factors, cognitive, emotional, behavioral and motivational measures. The questionnaire has 34 questions devoted to behavioral skills, motivation and expectations mental set 7 questions, 3 questions 3 questions cognitive skills and emotional measures would suffice. In order to estimate the scale of Cronbach's alpha reliability coefficient of correlation coefficient between the two (retest) used and to assess the internal consistency using Cronbach's alpha scale and subscale is used. Social competence questionnaire alpha coefficient obtained after the removal of items and had low correlation with the total score alpha is equal to 0.884 . This shows that the questionnaire has acceptable internal consistency coefficient, this questionnaire also in terms of content validity were examined according to theoretical and backed by Felner, in the view of experts in psychology and psychometric validity was confirmed and its logic. evaluated.

Styles Identity: Identity styles in this study by Bennion and Adams identity status questionnaire (1998) are

4 Questionnaire subscales advanced identity, the identity of late, premature identity, the identity is disturbed. Cronbach's alpha for internal consistency of the questionnaire is $75 \%$. In the open test $93 \%$ in half is the $68 \%$

\section{Method of Implementation of Research and Two Intervention Methods}

One of the training interventions methods, education, Drozila \& Gold Fried does social problem solving, in this model, there are two relatively independent and public components: orientation toward problem solving skills.

The objectives of this model are:

- One cannot identify your issues.

- Help the person who cannot use regular method to overcome everyday problems and current.

- The person helped to identify the resources that are at its disposal and use them to solve their problems, take advantage.

- Sense of control over the situation

- Enrich the individual in solving problems they will face in the future

Six step model: general orientation, define and formulate the problem, producing innovative solutions, decision making, implementation and verification solutions (Zoorila and Sheidi, 1991). It is expected due to other background research for this model to be taught during the seventh session (Ahadi et al., 2009, Bahram Giri et al 2001, Shahbazi et al., 2012). Another intervention courses, training schemes centered. As mentioned in Methods in parallel to another 25member group is oriented training scheme. (Protocols of these classes is provided in Appendix), according to Yang (1991), some people due to children's negative experiences, form the basic schema incompatibility that way of thinking, feeling and behavior and social relations, and sincerely and other aspects of their lives will affect next. Young believes that Schema because of unfulfilled basic emotional needs arise childhood, these needs include secure attachment to others, self-sufficiency and identity, freedom of expression needs and emotions in a healthy, self-motivation realistic limits 
and restraint (Yang et al., Translated by Hamid Pour and Anduze, 1386).

According to child development schemes need answers to the five areas of cuts and rejection, impaired autonomy and performance, orientation vigilant too and inhibition are divided, each consisting of several schemas (Young, translation Sahebi and Hamid Pour, 1997). When needs are not satisfied by a particular schema may be created impact on relations (Young and Glosko, 1997). In this study, we try to teach some of the schema schema-driven prime of youth to review and correct. Given that the schema-based training protocols based on research objectives determined by the investigator and according to the same research-based scheme is expected to around 7 sessions.

\section{Findings}

Since the objective of this study was to compare groups schemas and problem-solving research in pre- treatment and after the test and identity styles and social competence are more than one in scale; therefore, to analyze data from multivariate analysis of covariance was used. It should be noted that before performing multivariate analysis of covariance assess the assumptions of normality, homogeneity of variances were considered data. As well as to the effectiveness of problem solving therapy and schema therapy in both pre-test and post-test, paired t-test was used.

First hypothesis: there are significant differences between the effectiveness of schema-based education and social problem solving training on social competence in adolescents.

Table 1. Results of multivariate tests to check the problem and schema therapy treatment group differences in social competence

\begin{tabular}{ccccccll}
\hline $\boldsymbol{\eta}_{\mathbf{p}}{ }^{2}$ & sig & $\mathbf{D f}_{2}$ & $\mathbf{d f}_{1}$ & $\mathbf{F}$ & Value & Variable & Source \\
\hline 0.42 & 0.001 & 41 & 4 & 7.52 & 0.42 & Pillais Trace & \\
0.42 & 0.001 & 41 & 4 & 7.52 & 0.57 & Lambda Vyklz & Group \\
0.42 & 0.001 & 41 & 4 & 7.52 & 0.73 & Hotelling effect & \\
0.42 & 0.001 & 41 & 4 & 7.52 & 0.73 & Bighest root & \\
\hline
\end{tabular}

The results presented in Table 1 show that the effect of group ( $\eta 2=0.42,0.001>P, F=7.52, T=0.73$ ) is significant. In other words, the profile of schema therapy and problem solving therapy groups and the average pretest and then test the social competence variable, there were significant differences in levels of less than 0.05 .

Table 2. Analysis of variance test results between subjects for social competence

\begin{tabular}{ccccccll}
\hline $\boldsymbol{\eta}_{\mathbf{p}}{ }^{2}$ & sig & $\mathbf{F}$ & MS & df & SS & Variable & Source \\
\hline 0.15 & 0.007 & 7.88 & 70.51 & 1 & 70.51 & Cognitive skills & \\
0.10 & 0.03 & 4.90 & 25.05 & 1 & 25.05 & Emotional skills & Group \\
0.30 & 0.001 & 19.25 & 107.88 & 1 & 107.88 & Behavioral skills & \\
0.06 & 0.08 & 3.11 & 22.14 & 1 & 22.14 & Motivational skills & \\
\hline
\end{tabular}

Results Table 2 shows the average social competence and problem-solving schema between the two treatment groups in the three components of social competence, cognitive skills ( $F=7.88 ; 0.001>P)$, emotional skills ( $F=4.90 ; 0.03>P)$ and behavioral skills $(F=19.25 ; 0.001>P)$ there is a significant difference between the two treatment groups in mean score of problem-solving and schemas. So that female students at post-test in terms of group therapy and cognitive schemas, behavioral, emotional and social competence in a better and more desirable than female students with problem solving therapy. However, in terms of social competence components motivational skills ( $F=3.11 ; 0.08>P$ ) significant difference between the two groups of students schemas and problem-solving therapy was not observed. So we can say that schema-based education and treatment of problem-solving therapy compared with three components in promoting social competence; cognitive skills, emotional skills, behavioral skills of female students is effective. However, the impact and effectiveness of motivational skills component doses of both treatments was relatively the same and the difference between the two treatment groups was observed in terms of the effectiveness of social competence motivational skills.

The second major hypothesis: there is a significant difference between the effectiveness of Schema-based education and training, social problem solving scenarios identity of teenagers. 
Table 3. Results of multivariate analysis to examine the differences in problem solving therapy group and schema therapy in styles of identity

\begin{tabular}{ccccccll}
\hline$\eta_{\mathbf{p}^{2}}$ & sig & $\mathrm{Df}_{2}$ & $\mathrm{df}_{1}$ & $\mathbf{F}$ & Value & Variable & Source \\
\hline 0.53 & 0.001 & 41 & 4 & 11.62 & 0.53 & Pillais Trace & \\
0.53 & 0.001 & 41 & 4 & 11.62 & 0.46 & Lambda Vyklz & Group \\
0.53 & 0.001 & 41 & 4 & 11.62 & 1.13 & Hotelling effect & \\
0.53 & 0.001 & 41 & 4 & 11.62 & 1.13 & Bighest root & \\
\hline
\end{tabular}

The results presented in Table 3 show that the effect of group ( $\eta 2=0.53,0.001>P, F=11.62, T=1.13$ ) is significant. In other words, the profile of schema therapy and problem solving therapy groups and the average of test and post-test in the identity of variable styles there are significant differences in levels of less than 0.05 .

Table 4. Test results between subjects analysis of variance for identity style

\begin{tabular}{ccccccll}
\hline$\eta_{\mathrm{p}^{2}}$ & sig & F & MS & df & SS & Variable & Source \\
\hline 0.06 & 0.60 & 0.26 & 9.66 & 1 & 9.66 & Advanced Identity & \\
0.18 & 0.003 & 9.99 & 169.32 & 1 & 169.32 & Early identity & Group \\
0.09 & 0.03 & 4.74 & 158.36 & 1 & 158.36 & Late identity & \\
0.38 & 0.001 & 27.76 & 72.03 & 1 & 72.03 & Confused identity & \\
\hline
\end{tabular}

Results Table 4 shows the mean between the two treatment groups in solving the problem of identity styles and identity schemas in three styles; early ( $F=9.99 F ; 0.003>P)$, late $(F=4.74 ; 0.03>P)$ and agitated $(F=27.76 ; 0.001>P)$ significant difference between problem-solving schema in grades two treatment groups. So that female students have lower social competence in the post-test schema therapy early identity in terms of style, and agitated in a better position and better late than female students with problem solving therapy group with low social competence. However, for advanced identity style $(F=26 ; 0.60>P)$ significant difference between the two treatment groups and problem-solving schema-school students with low social competence was not significant. It can be said that compared to treatment schema-based education and treatment of problem-solving styles on upgrading the components of identity; early, late and chaotic school students with low social competence is more effective. But in the field of advanced identity style impact and effectiveness of both treatment groups was relatively equal and differ both in terms of their effectiveness.

First hypothesis: schemas-based education has a significant effect on adolescent social competence.

To address this hypothesis, we used paired t-test or affiliates.

Table 5. The results of t-test and pre-test and post-test compare the scores of social competence for schema therapy group

\begin{tabular}{ccccl}
\hline sig & df & t & Differences between the means & Variable \\
\hline 0.001 & 24 & $12.62-$ & $16.44-$ & Cognitive skills \\
0.001 & 24 & $15.48-$ & $17.92-$ & Emotional skills \\
0.001 & 24 & $36.37-$ & $18.42-$ & Behavioral skills \\
0.001 & 24 & $35.10-$ & $23.36-$ & Motivational skills \\
\hline
\end{tabular}

According to Table 5 paired $t$ test results showed that there is a significant difference between the average post-test and pre-test, school girls group schema therapy in terms of components and the subscales of social competence, cognitive skills $(0.001>P)$, emotional skills $(0.001>P)$, behavioral skills $(0.001>P)$ and motivational skills $(0.001>P)$. So that grades student girls schema therapy group were significantly higher than their pre-test scores are different, thus the first hypothesis of this study is approved and accepted, and we can say that, Schema-based education has a significant positive effect on adolescent social competence.

The second sub-hypothesis: social problem solving significant effect on adolescent social competence.

To address this hypothesis, we used paired t-test or affiliates. 
Table 6. - t-test and pre-test and post-test to compare the scores of social competence for problem solving therapy

\begin{tabular}{ccccl}
\hline sig & df & $t$ & Differences between the means & Variable \\
\hline 0.001 & 24 & $24.06-$ & $19.00-$ & Cognitive skills \\
0.001 & 24 & $35.36-$ & $21.80-$ & Emotional skills \\
0.001 & 24 & $27.93-$ & $22.72-$ & Behavioral skills \\
0.001 & 24 & $39.43-$ & $23.72-$ & Motivational skills \\
\hline
\end{tabular}

According Table 6 paired t test results showed that there are significant differences between the average post-test and pre-test school students in problem solving therapy group in terms of components and sub-scale social competence, cognitive skills $(0.001>P)$, emotional skills $(0.001>P)$, behavioral skills $(0.001>P)$ and motivational skills $(0.001>P)$. So that grades school students in problem solving therapy group were significantly higher than pretest scores between them, so the second hypothesis of this study is approved and accepted, and we can say that, problem-solving education on adolescent social competence has a significant positive effect.

The third sub-hypothesis: identity-based training schemes teens significant effect on moods.

To address this hypothesis, we used paired t-test or affiliates.

Table 7. Results of t-test and pre-test and post-test to compare scores for identity states Schema Therapy

\begin{tabular}{ccccl}
\hline sig & df & $\mathbf{t}$ & Differences between the means & Variable \\
\hline 0.001 & 24 & $17.67-$ & $24.72-$ & Advanced Identity \\
0.001 & 24 & 10.40 & 13.52 & Early identity \\
0.001 & 24 & 8.54 & 20.28 & Late identity \\
0.001 & 24 & 9.44 & 13.84 & Confused identity \\
\hline
\end{tabular}

According to Table 7, paired t test results showed that there is a significant difference between the average post-test and pre-test, school girls style identity group schema in therapy advanced $(0.001>P)$, early $(0.001>P)$, late $(0.001>P)$ and motivational $(0.001>P)$. So that grades student girls schema therapy group were significantly higher than their pre-test scores are different, the third hypothesis of this study was approved and adopted and it can be said that the training scheme based on moods and styles adolescent identity is a significant positive effect.

The fourth sub-hypothesis: problem-based learning has a significant effect on adolescent identity scenarios.

To address this hypothesis, we used paired t-test or affiliates.

Table 8. The results of t-test and pre-test and post-test to compare scores for group problem-solving scenarios identity

\begin{tabular}{ccccl}
\hline sig & df & $\mathbf{t}$ & Differences between the means & Variable \\
\hline 0.001 & 24 & $20.92-$ & $26.36-$ & Advanced Identity \\
0.001 & 24 & 17.05 & 16.20 & Early identity \\
0.001 & 24 & 9.16 & 23.92 & Late identity \\
0.001 & 24 & 10.95 & 16.16 & Confused identity \\
\hline
\end{tabular}

According to Table 8 paired $t$ test results showed that there is a significant difference between the average post-test and pre-test, school girls group problem-solving identity in terms of style; advanced $(0.001>P)$, early $(0.001>P)$, late $(0.001>$ $P)$ and motivational $(0.001>P)$. So that schoolgirls group problem-solving post-test scores were significantly higher than their pre-test scores are different, the fourth sub-hypothesis of this study is approved and accepted and we can say that, problem-based education has a significant positive effect on adolescent identity moods and styles.

\section{Discussion and Conclusion}

Emotional and social motivation and identity scenarios provide students with appropriate teaching strategies, these students will be unable to prevent and provides practical strategies to educators.

Cognitive skills, emotional skills, behavioral skills of female students are effective. But the impact and effectiveness of both treatment components motivational skills are relatively equal and the difference between the two treatment groups was observed in terms of the effectiveness of social competence motivational skills. The results showed that schemabased education and intervention has been more successful because of it, schema-based education was more effective 
measures against social acquire problem-based learning. Schema effect on the components of social competencebased skills training such as cognitive, behavioral, and emotional and motivational researches have been studied. Pajars and Shank studies (2015), Pooirazli (2013), Whitelife, Smith kron (2000) and Marsh (1990) the effect of attitude or relationship-based training schemes have been confirmed. Frey (2015) in their study indicated that if a person's emotional skills and emotional control your emotional connection fails, social adaptation stage he is in trouble and the persistent negative consequences and one in particular in terms of independence, socialize with peers and solve efficient manufacturer of various subjects are in trouble. Nabors, Reynold and West (2010) on schema-based skills training on reducing aggression, depression, increased confidence, increased social competence and responsibility of students achieved positive results. Swanson and Malone (1992) social competence of students with learning disabilities and metaanalysis examined the ordinary. The results showed that students with learning disabilities in social problem solving skills of 79 percent of students are weaker than normal. Many studies about the effectiveness of Schema-based skills training on various aspects of social skills and overall social competence, and in most cases the effects of this training on behavioral skills and emotional and motivation, separately investigated and few studies have compared the effectiveness of Schema-based skills against social problem solving skills has been on the components of social competence. So it can be said in explaining the hypothesis that cognitive schema-oriented strategies in this study were trained.

Help people to be able to question the schemas, sound healthy to bring his mind, thus enabling their healthy mentality. The results of this hypothesis by finding boasts Wiley (2010), Hallam et al. (2012), Swanson and Malone (1992), Nabors, Reynold and West (2010), Frey (2015), Pajars and Shank (2015), Pooirazli (2013), Whitelife, Smith kronor (2000) and Marsh (1990) is consistent. As the results showed, compared with the treatment schema-based education and treatment of problem-solving styles in upgrading the components of identity early, late and chaotic school students with low social competence is more effective. However, in the field of advanced identity style had no effect and efficacy of both treatment groups was relatively equal and differ both in terms of their effectiveness.

Yang early maladaptive schemas is to be believed (1990), early maladaptive schema structures deep understanding of beliefs about the "identity" and "self" are organizations schema of reality as a result of empirical experience of the environment grow. Including conceptual approach and philosophy adopted in the development of therapeutic schema model with many models such as the approach to the field of pathology and psychotherapy, cognitive - behavioral, constructivism, fluid dynamics, object relations and gestalt overlap. Although some aspects of schema therapy overlap with these models are, however, important differences with them. However, schema theory contains concepts that are introduced in many schools of psychology, but none of these schools with schema therapy does not completely overlap. The results of this hypothesis with the findings of Darko Malkolom (2008), Samavi and Sajjadi (2011), Willy Bold (2010), Hallam et al (2012) are consistent.

As the results became clear, Schema-based education on adolescent social competence subscales (cognitive skills, emotional skills, behavioral skills and motivational skills) affect and this hypothesis is approved and accepted and we can say that, schema-based education has a significant positive effect on adolescent social competence. Schema effect on the components of social competence-based skills training such as cognitive skills, behavioral, emotional and motivational researches has been studied.

The results obtained in this study are consistent with most research. Studies Pajars and Shank (2015), Poeerazly (2013), Whitelife, Smith Kronor (2000) and Marsh (1990) the effect of attitude or relationship-based training schemes have been confirmed. Frey (2015) in their study indicated that if a person's emotional skills and emotional control your emotional connection fails, social adaptation stage he is in trouble and the persistent negative consequences and one in particular in terms of independence, socialize with peers and solve efficient manufacturer of various subjects are in trouble. In explaining these results, we can say schema-based education and intervention will be successful because of it this way, schema-focused cognitive strategies to help people to be able to question the schemas, create a healthy voice in his mind, thus enabling their healthy mentality and to improve attitudes, improved relationships and thus enhance their competence and adequacy, particularly social competence. As the results became clear, social problem solving training has a significant positive effect on adolescent social competence. Social skills are especially targeted problem solving skill set of behaviors, connected, fit the situation, learn, and are under the control. Problem-solving skills makes people socially can alter behavior to suit conditions and overcome difficulties (Mohammadi Rad et al., 1387). This skill is very important, especially in cognitive control skills. Therefore, the person who is socially shortage of skills, they may not learn the main element of social skills but the thought processes do not have to use these elements (Bijstra et al., 2014). Therefore, the results obtained in this study cannot be explained in this way is that, problem-solving skills, logical thinking process that helps people so when faced with problems, several solutions search and then select the best solution this effect was especially important during adolescence. These skills and apply it in practice teenage life, resulting in improved social interactions and be their competence and social competence. 
The results of this hypothesis with the findings of Frey (2015), Bijstra et al (2014), Poeerazly (2013), Whitelife, Smith kronor (2000) and Marsh (1990) is consistent. As the results became clear, the state-based training scheme and identity styles girls have a positive and significant effect. To explain these results it can be successful in the role of individual identity formation in adolescents based on correct social experiences of dealing insisted. Teenagers need to recognize and separate from others until their mental balance is set, but if the frustration and uncertainty in the ages to be replaced and instead the contact with people, instead of moving into recession reclusive teenager and grace to achieve abnormal and confused identity (Clark, 1992; Hosseini-Nasab, et al., 2009). In other words, identity in adolescence as well as physical growth, cognitive, social and emotional and given that the scheme as a part of the organization is essential to understand the experiences of one's life and it looks and schemes are formed mainly as a result of the experiences of sensitive. The core of the personality and interpersonal relationships and identity through schemes and it can affect moods. Result of this hypothesis with the findings of Clark (1992), Hosseini-Nasab et al (2009), Samavi and Sajjad (2011), Hallam et al. (2012). As the match results it was recognized that social problem-solving skills training on identity styles, advanced, early, late and motivational impact. To explain these results we can say that identification of an inner self, including their construction, the system of beliefs, desires, ideas, skills and history of separation. The main task of identity formation begins in high school and continued through college-age seriously. Unlike the clutter structure (deconstruction) that people experience in early adolescence, high school students are more likely to forgive or restructure they restructure their identity, while people in early adolescence childish notions of overwhelm, kids in high school are often a sense of cohesion or reorganize themselves physically, sexual feelings, assessment of current and expected capabilities and roles are trying. Ourlofski et al (1973), Marcia (1976), Ashmn (2004) Krueger And Green (2008), Krosty et al (2014) in their study that found similar results to this study. It seems life skills-based education as social problem-solving skills during the teen sitting greatest effect on the identity of the juvenile, other times. If the study also showed that problem-based learning, the identity of all the states in adolescents is a significant positive effect.

\section{References}

Aboulghasemi, Abbas. Jamaloee Rezaei, Hassan. Narimani, Mohammad. Zahid Bablon, Adel. (2011). Comparison of social competence and its components in students with learning disabilities and students with low academic achievement, medium and high. Journal of Learning Disabilities, the first year, 1.123 to 140 numbers

Ahadi, B.. Mirzaee, Perry. Narimani, Mohammad. Abolqasemi, Abbas. (2009) The impact of social problem-solving approach on social adjustment and academic performance of students shy. Research on Exceptional Children from 0.9 to 3 193-202

Amani, Ahmed. Keshavarz Afshar, Hossein. Esfandiari, Hossein. Bazvand, Fatima. Abdullahi, Narmin. (2013). The relationship between early maladaptive schemas and identity styles in students. Journal of Behavioral Sciences .2013: 7-1

Bahram Giri, F. (2001), The effect of problem solving training in social skills mildly retarded students. Master's thesis, Teacher Training University

Byani, Ali Asghar, Ranjbar, M. Bayani, Ali (2012) the relationship between social problem solving ability in students with depression and social phobia Mazandaran University of Medical Sciences, 22 (94): 92-99

Bayrami, M. (2006). The impact of social skills training on social competence and predict changes in academic achievement based on the components of social competence. Doctoral thesis. Tarbiat Moallem University of Tehran. Faculty of Psychology and Educational Sciences

Parandin, SB (2006). Social and normative sphere of competence questionnaire in adolescents in Tehran . master thesis

Javaheri, Azam (2014). The effectiveness of problem solving to decrease identity crisis teen girls. Mai Conference of Education and Psychology, Shiraz. Enterprises opinion makers, young

Khorahleh, S. (2014). Comparison between the identity and attachment styles and early maladaptive schemas in addicts and nonaddicts. Master thesis. Tehran Tarbiat Moallem University - Faculty of Psychology and Educational Sciences

Khoshkam, Zahra. Malekpour, M. Maulvi Hossain. (1387). The effectiveness of group problem solving training on social skills for students with visual impairment. Research on Exceptional Children 8 (2): 141-156

Dehshiri, G. (2009). The relationship between religiosity and identity crisis among high school students in Yazd city. Scholar behavior. Volume 6, Number 13

Shahbazi, Sarah. Heidari, Mohammad. (2012). The effect of social problem solving model Zvryla \& Gold Fried on problem-solving skills of nursing students. Journal of Nursing Tehran University .25/ 76 1-9

Alikhani, Ali Akbar. (. 2014). The theoretical foundations of identity and identity crisis, Tehran: Center for Humanities and Social Sciences (SID)

Kazemi, Reza, Momeni, Seville. Kiamarsi, Azar. (2011). The effect of life skills training on students' social competence proband dyscalculia. Journal of Learning Disabilities (1) (1): 94-108

Klinke, Al-kris. (2004). . Life skills Shahram Mohammad Khani. Tehran:.

Mohammadi, Seyed Yunes. (2014). Efficacy of treatment is negative assessment-based training schemes spouses from each other. Journal - Clinical Psychology Laboratory (1) (1): 10 
Moradi Dalir, Z. (2014). Compare the effectiveness of emotional regulation and social problem solving training on social skills and academic adjustment middle school students in Urmia 93-92 school year master's thesis. Ministry of Science, Research and Technology - University of Urmia

Motamedi,H. Haj Babaei, H. Biglarian, or. Sloklaee Fallah, M. (2012). The effect of increasing social competence skills training, problem solving adolescents. Journal of Social Research. Fourth year: 14: 17-30

Ghadimi Fesqendis, Mitra. (2014). Investigate the relationship between body mass index with active and passive modes of identity among female students in secondary schools in five regions of Tabriz. Master thesis Ministry of Science, Research and Technology. Urmia University.

Adams, C. R. \& montemayor, R. (1989), Biology of adolescent behavior and development. New Yourk: sage publication.

Anme, T. et al., 2013, Validity and reliability of the Social Skill Scale (SSS) as an index of social competence for preschool children, Journal of Health Science, 3(1).

Anme, T. et al., 2013, Validity and reliability of the Index of Child Care Environment (ICCE), Public Health Frontier, 2(6).

Altun, I. (2013). The perceived problem solvingability and values of student nurses andmidwives. Journal of Nurse Education Today,28, 575-53.4.

Aunola, K., Statin, H., \&Nurmi, J.E. (2000). Parnting Style and adolescent achievementStrategies.Journal of Adolescence, 23, 205 222.

Ansburge, P. L., Dominowski, R. L. (2000).Implementation and outcome of training problem solving for adolescents withdepression. Journal of Adolescence, 53, 673-616

Arslan, C, (2014), An investigation of the interpersonal conflict resolution and problem solving approaches with respect to attribution complexity, Unpublished doctoral dissertation, Selcuk University, Konya, Turkey.

Blankstein K R , Flett G L , Batten T .Text anxiety and Problem solving self affraisal of college students .Journal of social Behavior and personality.(1989); 4:581-543

Beyers W, Goossens L. Dynamics of perceived parenting and identity formation in late adolescence. J Adolesc. 2008; 31(2):165-84.

Biggam F, Power KA. Controlled problemsolving, group-based intervention with vulnerable incarcerated young offenders. Int $\mathrm{J}$ offender Ther Comp Criminol 2012; 46(6): 676-698.

Castonguay, L. \& Hill, C. E. (Eds.) (2007). Insight in psychotherapy. Washington DC: American Psychological Associatio

Dobson S K. (1988)Cognitive behavioral therapies New York.Guilford press.

D'Zurilla, T.J., Goldfried, M.R, (1971), Problem solving and bihavior modification, Journal of Abnormal Psychology, 13, 437-426.

D' Zurilla TJ, Nez u AM, Maydeu -Olivares A.( 2002) Manual for the social problem-solving inventory-revised. 1thed. New York: MultiHealth Systems;. 20.

D' Zurilla TJ, Nezu AM. Development and preliminary evaluation of the social problem solving inventory. Psychos Assess 1990; 2(2): 156-163.

Faber AJ, Edwards AE, Bauer KS, Wetchler JL. Family structure: Its effects on adolescent attachment and identity formation. Am J Fam Ther. 2003; 31(4):243-55.

Funkhouser, C., \&Denois, J (1992). The effect of problem solving software on problem - solving ability. Journal of Resarch on compution in education, 24(8), 883-847.

Gesten E L , Weissberg R D , Amih D L ., smith J K .(1988)To social problem-solving training Skill-based approach to prevention and treatment in psychoeducational interventions in the school New yourk . prgamon press .

Hegel, M. T., Barret, J. E. and Oxman, T. E. (2000).Training therapists in problem solvingtreatment of depressive dispersion primarycare. Journal of Families System and Health, 13, 428-485.

Heppner D, Witty T E, Dixon W A. (2006)Problem solving appraisal and human adjustment a review of research using the problem solving inventory Journal of counseling psychology. 2336; 82: 813.

HeppnerD,Peterson G.(1982)The development and implication of a personal-problem-solving-inventory. Journal of counseling psychology.1132;22:66-36.

Kim, I. Y. (2011). The effects of assertiveness selective mutism. Journal of Behavior Modification, 28, 132-115.

Karl-Heinz, Arnold. Carola Lindner-Mülle. (2012). Assessment and development of social competence: introduction to the special issue. Journal for Educational Research. Vo I 4, No 1.p124-135.

Lili Tian, Mengmeng Han, E. 2014.Scott Huebner .Preliminary development of the Adolescent Students' Basic Psychological Needs at School Scale .Journal of Adolescence, 37: 3, , 257-267

Llobet,Paula.( 2014) .Overcoming Fear: Group Hypnotherapy for the Treatment of Phobias Paperback .

Mcmurran M, Christophr G. Social problem solving, anxiety, and depression in adult male prisoners. Legal and Criminological Psychology 2009; 14(1): 101-107.

Marlow RC. Research methods for generalist social work. 5thed. Belmont, CA: Brooks Cole; 2011.

Moos, R. h, S Billings, P. (1990), Risk, resistance and psychological distress. Journal of Abnormal psychology, 90, 3-13.

Smokowski, Paul R . Franser, M., Galinsky, E., Smokowski, P., Day Tevzian, A., Rose, A. \& Guo, S. (2014). Social information processing skills training to promote competence and prevent aggressive behavior in the third grads. Conselling and clinical psychology, 73(6), 1045- 1055.

Stephenson, C. L. (1999). Trust and claims of identity: A case study of masters swimming. Avante,5, 23-38.

Stephenson, C. L. (2002). Seeking identities: Towards an understanding of the athletic careers of masters swimmers. International Review for the Sociology of Sport, 37, 131-146. 
Ssylvia,kowak.Yeuny,Jerf.Low,Andrew,Herman.H.M.chery.(2015). The roles of emotional competenceand social problem solving in the relation ship between physical abuse and adolescent suicidal ideatation in china . child abuse and neglect.44:117-129.

Stephenson, Donald J. (1995)Achievement motivation as a factor Related to the Diagnostic problem solving Effectiveness of student of automotive technology. University Michigan .

Spivak G,shure M. (1982)the problem solvig approach to adjustment. san franciscon.jossey-bass-.

Tellado G. (2013)An evaluation cases the implementation and Evaluation of a problem solving training program for adolescents. Indian university of pensylvania USA.

Usher, L .V. Burrows. A. C.(2015). Social competence with an unfamiliar peer in children and adolescents with high functioning autism: Measurement and individual differences. Research in Autism Spectrum Disorders.17, , 25-39.

Wichroski, $F(2001)$. Caregiver social problem solving abilities and family member.Adjustment to recent onset physical disability.

Zarb J .(2010). Assessment of cognitive -behavior therapy in teenager's. Tehran. Roshed. Press.

Zarb J . (1990).Cognitive-Behavioural assessment and therapy with adolescents .New York :Brunner/Mazel.

Zarb J. (1990)Perseptions and response styles adolescent girl with family problems. Journal of referred youth and adolescence. 1113; 11: $227-223$. 